\title{
MONITORING THE SPATIAL DISTRIBUTION OF DEGRADED LANDS IN SIRSA DISTRICT
}

\author{
Promila $^{1 *}$, K. E. Mothi Kumar ${ }^{2}$, Praveen Sharma ${ }^{1}$ \\ ${ }^{1}$ Guru Jambheshwar University of Science and Technology, Hissar, Haryana - pb091190@yahoo.in, praveen.gju@gmail.com \\ ${ }^{2}$ Haryana Space Applications Centre, Hissar, Haryana - kemk@ harsac.org
}

Commission V, SS: Natural Resources Management

KEY WORDS: soil degradation, wind erosion, anthropogenic, water logging

\begin{abstract}
:
In this paper, study on monitoring of kind, extent and degree of severity of degraded lands was conducted in Sirsa district ( $29.53^{\circ} \mathrm{N}$ $75.02^{\circ} \mathrm{E}$ ) of north western Haryana with the help of geo-spatial techniques. Efforts have been made to identify and map the degraded lands of the district on 1:50.000 scale using LANDSAT TM (1995) and IRS LISS-III (1A/B FCC; 2005-06 and 2015-16) satellite imagery. The area under various degraded land categories was computed for different seasons which reveal that wind erosion was major cause of soil degradation problem in the district since 1995. The area under degradation due to wind erosion was followed by water logging, anthropogenic activities and salinisation. Although the area occupied by anthropogenic activities was found to be low but their impact on environment is long term than naturally degraded soils. A significant decline is observed in all the degradation classes (except brick kilns) in successive years but however, water logging (permanent) shows increasing trend in 2005-06 and then decline in 2015-16. The reasons have been sorted out to explain the changing dynamics of degradation. The district was found to be degraded by various categories of land degradation subjected to slight to moderate degradation. The degraded lands have shown sharp decline from $28.4 \%$ in 1995 to $6.22 \%$ in $2015-16$ of total geographical area of the district.
\end{abstract}

\section{INTRODUCTION}

Soil is the natural resource which needs utmost care in context of food security for the growing population. Mapping of degraded soils hence, becomes one of the most important requirements for managing and conserving them. The processes associated with soil degradation are site-specific and differ in their kind, intensity and areal coverage. Identification, mapping and characterisation of the specific sites could help to formulate the developmental plans for the affected area. The study area is found associated with various forms of degradation processes which includes sand dunes, water logging, salinity and anthropogenic. The alarming losses in economic revenues and agro-system services have revealed an acute need for monitoring of land degradation and analysis of its cause in order to advice decision makers on spatial targeting of land rehabilitation measures. Several literatures have cited remote sensing as an essential tool to measure soil degradation (Sehgal and Sharma, 1988; Oldeman et al, 1990; Saxena et al, 1991; Raina et al, 1991, 1993). Remote sensing and GIS have emerged effective technologies for detecting, assessing, mapping and monitoring degraded lands with synoptic view of the area allowing for rapid mapping and monitoring of waste lands. The present study focuses on the use of remote sensing and GIS to identify and map the extent of degraded areas in Sirsa district of western Haryana since 1995. The datasets on the type of land degradation were generated, tabulated and mapped. The soil degradation assessment is a measure of severity of area affected by degradation which could be considered as a measure to conservation of soil resources and restoration of productivity of deteriorated soils.

\section{MATERIALS AND METHODS}

\subsection{Study Area}

The Sirsa district is located in the north western part of Haryana state covering an area of $4268.17 \mathrm{~km}^{2}$ located between $29^{\circ} 13^{\prime}: 29^{\circ} 59^{\prime}$ north latitudes and $74^{\circ} 30^{\prime}: 75^{\circ} 7^{\prime}$ east longitudes. The district comprises of four tehsils: Sirsa, Dabwali, Rania and Ellenabad. These tehsils are further sub-divided into seven blocks: Baragudha, Dabwali, Ellenabad, Nathusari Chopta, Odhan, Rania and Sirsa. According to 2011 Census, Sirsa district has a population of $1,295,189$ with a population density of 303 inhabitants per square kilometre. The Ghaggar, an important seasonal river in the district is a major drainage of the area having a length of $85 \mathrm{~km}$ in the district. Physiographically, the district is characterised by three distinct features, i.e. Upland plain, Alluvial bed (flood plain) of river Ghaggar and Sand dunes clusters. The soils of the district are of two types: Sierozem soils found in areas with annual rainfall of 300-500 $\mathrm{mm}$ and Desert soils occurring in areas with rainfall measuring less than $300 \mathrm{~mm}$. The climate of the district is of tropical desert type: arid and hot, which is mainly dry hot summer and cold winter except the monsoon period when moist air of oceanic origin penetrate into the district. The normal annual rainfall of the district is $318 \mathrm{~mm}$ which is unevenly distributed (CGWP).

\subsection{Database Preparation}

This process involved creating mosaics of Landsat TM for 1995, and IRS-1B LISS III for 2005-06 and 2015-16 data for three seasons (rabi, kharif and zaid) covering the command area and their geometric registration to reference image. The datasets were subsequently mosaicked using an image to image

* Corresponding author 
registration algorithm by identifying common ground control points (GCPs) and computing second order polynomial transform to sub-pixel accuracy. The root mean square error (RMSE) was reduced to 0.02. Prior to registration and mosaicking, the area of interest (Sirsa district) was extracted from sub-scenes of satellite imagery by sub-setting. Further, interpretation was performed on the prepared datasets.

\subsection{Mapping soil degradation}

Criteria suggested by Kassas, 1995 for extension of desert area, Kapoor and Kavdia, 1994 for assessment of water logging were adopted for identifying the area degraded due to different types and intensity of degradation process. The extent to which degraded lands were found was based on the visibility on the satellite image. The further classification of degraded land class was done based on the observations of the three seasons (rabi, kharif and zaid).

\subsection{Interpretation of remote sensing data and field studies:}

Geo-coded sub-scenes IRS 1A (path/row) false color composite image with band 2, 3 and 4 obtained from HARSAC, Hissar and Landsat TM downloaded from USGS were used on 1:50,000 scale to monitor the status of degraded lands in Sirsa district since 1995 . The satellite images were visually interpreted based on the tonal characteristics of different degradation process. Wind erosion was classified into three categories: Sheet Erosion. Partially Stabilised Dunes and Stabilised Dunes. Partially Stabilised Dunes (Psd) appeared light grey to medium grey with light yellowish tones in regular or irregular shape while stabilised dunes (Sd) having similar tone were found covered with pink mottles during rainy season forming discrete patches. Waterlogged soils were either permanently or seasonally saturated with water. These are found associated with depressions in inland plains, irrigated areas or plains with higher water table. They appear light blue to dark blue (permanent) or medium to dark grey (seasonal). Salt-affected soils are present in discrete patches appearing light grey to white on standard FCC. Anthropogenic areas mainly occupied by brick kilns present in isolated patches give rise to mottling pattern. They are found associated with urban areas and its surrounding, located along trafficable road network and give dull white to light yellow appearance. The boundaries of each kind of degradation with their intensities were delineated in the form of demarcated polygons. A ground truth survey for 201516 was conducted for cross examining the delineated features in the field and the co-ordinates of the feature class were recorded using hand held GARMIN GPS $72 \mathrm{H}$. The demarked features were then co-related with ground manifestations. Terrain characteristics were also observed at each degraded site including water logging, wind erosion in terms of sand dunes etc.

\section{RESULTS}

Sirsa district $\left(4268.17 \mathrm{~km}^{2}\right)$ is affected by various types of land degradation. The total area covered at present under degraded class of soils is $265.64 \mathrm{~km}^{2}$ which accounts for $6.22 \%$ of total area of district which reduced from $1211.49 \mathrm{~km}^{2}$ in 1995 to $542.07 \mathrm{~km}^{2}$ in 2005-06. The degradation problem of soils was observed mainly due to wind erosion, followed by water logging, salinisation and anthropogenic. Ground truth surveys reveal that salinisation is found associated with water logged soils.

\subsection{Area degraded due to wind erosion}

Degradation studies of the district reveals that wind erosion affected $83.4 \%$ of degraded lands in $1995 ; 57.4 \%$ in $2005-06$ and $87.1 \%$ in $2015-16$. This depicts that at present most of degraded land remain affected by wind erosion. The southern part of district is affected mostly by wind erosion due to presence of sand dunes in the area. The sand is loose with coarse texture which makes it fly easily and get deposited in the nearby areas. The dunes are categorised into stabilised, partially stabilised and un-stabilised dunes on the basis of presence of vegetal cover.

3.1.1 Area under partially stabilised dunes (Psd): Dunes possessing a vegetal cover of $40-60 \%$ are categorised under partially stabilised dunes. These appear as light to medium grey with light yellowish tone on the satellite image and are also associated with red tinge due to rabi crops. The area is also found to be cultivated with crops like gram and pearl millet which often result in loosening of the soils and its drift with the flowing winds accelerating the degradation process. The loose sand particles are coarse which marks low aggregate stability of soils due to which it gets blown off easily. The sand gets deposited forming sand piles and also covers the nearby fields reducing their productivity. Maximum area of wind erosion has been found to fall under this category. An area of $60.27 \mathrm{~km}^{2}$ in 2015-16 falls under this category. These areas are found to convert to stabilized dunes owing to cultivation due to improved irrigation facilities and have also been turned to plains by levelling by heavy machinery.

3.1.2 Area under stabilised dunes (Sd): These dunes posses a vegetation cover of $>60 \%$. The intensity of degradation under this category is low. These areas are often associated with medium grey to yellowish color and pink mottles of glooming seasonal grasses can be seen in rainy season. These dunes are often, brought under agriculture with the use of sprinklers for irrigation and can be seen as red tinge on IRS imagery and therefore the area appeared to increase from $33.89 \mathrm{sq} . \mathrm{km}$ in 2005-06 to 60.27 sq. $\mathrm{km}$ in 2015-16. However, in the month of May and June blowing strong winds loosen the upper surface of soils depositing the sand in form of sheets in nearby areas.

3.1.3 Area under Sheet Erosion (Sht): The displacement of sand unevenly forms a sheet over the underlying areas around the dunes. The deposition of sand reduces the yield capability of soils. Sheet erosion has undergone a declining trend (11.24 sq. $\mathrm{km}$ in 1995 to $6.12 \mathrm{sq}$. $\mathrm{km}$ in 2005-06 which have further reduced to 5.11 sq. $\mathrm{km}$ in 2015-16) either due to sand dunes stabilisation or even reduction in their area.

\subsection{Area subjected to waterlogging and salinization (WL/Se):}

Waterlogged conditions are likely to be found in the areas of introduction of canal irrigation without proper drainage and the rising ground water table. These conditions have also been generated as a result of paddy cultivation in the district. The soils get saturated due to seepage of water continuously which gives rise to filthy conditions of soils. The water is found stagnant on the surface at many places. Water logging is also responsible for salinity levels of soils. Based on the presence of waterlogged conditions in different seasons, it has been classified into seasonal and permanent water logging. 
Water logged soils are found in the canal command area, depression relief, underlying of hardpan at shallow depths, over-irrigation and presence of water table near surface. Medium to high texture soils are found in the canal command area which makes it very fertile but however, seepage from the canal, poor maintenance and over-irrigation raises waterlogged conditions in the soil making them loose their productivity. In many areas, water is also found stagnant over the surface in low lying areas. During dry season, the water at surface gets evaporated at several places leaving behind a crust of salt over the surface. The salt crust gives a white appearance to the surface. The unhealthy conditions of soil do not allow vegetation to grow on them contributing to economic loss.

Seasonal water logging marks less severe condition of soils and vegetation is found to grow on these soils but however, water logged conditions appear post-monsoon making them suitable for cultivation in one season. The severity of condition is found in permanently water logged soils, the water prevents soil from aeration making it difficult for roots to respire and the plant eventually dies. Water logging is found to affect a total of 3358.34 hectares in 2015-16 which declined from 22923.06 ha in 2005-06 and 38504.57 ha in 1995.

Salt affected soils are generally found associated with water logging but however, irrigation from ground water has also turned fertile land into salt affected. These occur presently in Ludesar, Nathusari Chopta and cover a total area of 5.76 hectare which has reduced from 130.12 ha in 2005-06. The vegetation cover was found to either missing or scarce dominated by salt tolerant bushes and non-palatable herbs. The severity of condition depends upon the Exchangeable Sodium Percentage of the soil. The higher ESP causes dispersion of soil particles reducing their aggregate stability.

\subsection{Area degraded by anthropogenic activities (Bk):}

The areas degraded by human interference with the environment are categorised under anthropogenic and have contributed to decreased biological productivity, diversity and resilience of land. Brick kilns are the major areas delineated under this category of wastelands. They are present in the vicinity of road network so as to be easily assessable to the people. The land under this category is turned bare and could not be made productive. The de-surfacing of soils for the use in formation of bricks also leads to topping off the upper fertile soil permanently. Removing plant residues also reduces soil organic matter content. LANDSAT and LISS-III data provides for a resolution of $30 \mathrm{~m}$ and $23.5 \mathrm{~m}$ respectively with which only clusters of kilns can be identified, however a significant rise in area under this category has been observed. The area estimated in 1995 was 17.18 ha which rose to 25.81 ha in 2005 and in 2015 an area of 73.57 ha has been found under brick kilns. This growth could be related directly to population explosion and growing modernization which puts more pressure on land.

\subsection{Change Detection Analysis:}

The change in area of degraded lands occurring over a period of 20 years has been summarised in Table 1 . The change has been observed by the shift of one category of degradation to another and also by normalisation of degraded lands by use of human power. Seasonal waterlogging in Ghaggar belt in 1995 was a result of flood which occurred in August 1995 but however, the dilemma of rising waterlogged conditions in 2005-06 could be explained by the fact that paddy cultivation was employed by farmers in this area.

\begin{tabular}{|l|c|c|c|}
\hline Category & \multicolumn{3}{|c|}{ Area (sq. Km) } \\
\hline & 1995 & 2005 & 2015 \\
Sheet Erosion & 11.24 & 6.11 & 5.11 \\
Partially Stabilised & 929.58 & 271.28 & 165.86 \\
Dunes & & & \\
Stabilised Dunes & 69.17 & 33.88 & 60.27 \\
Seasonal Waterlogging & 197.87 & 166.60 & 32.80 \\
Permanent Waterlogging & 1.94 & 62.63 & 0.78 \\
Salt Affected & 0.97 & 1.30 & 0.06 \\
Anthropogenic & 0.17 & 0.26 & 0.74 \\
\hline
\end{tabular}

Table 1. Area statistics of degraded land categories over the years.

The waterlogged areas have declined in 2015-16 due to reclamation of degraded areas artificially. The figures completely depicts that human interference can pose more threat to soil and are associated with resources expenditure for their reclamation. Salt affected areas have shown an increase in 2005-06 which occurred due to continuous use of ground water for paddy cultivation which lead to rise of salts on the surface leading to encrustation over the surface.

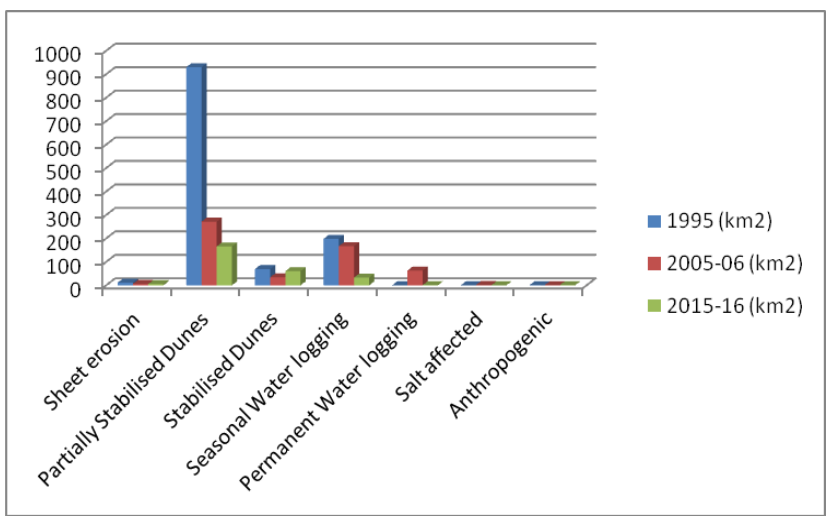

Figure 1. Graph depicting change in area of degraded lands.

The graph depicts changes in area of various categories of degraded lands. The dunes have been stabilised as we move from 1995 to 2015 which can be related to better irrigation facilities and more intensive farming practices. A tremendous increase in permanently waterlogged areas was found in 200506 which was a result of human activities associated with paddy cultivation which ultimately gave rise to filthy conditions of the soils. The change in various categories which aid in converting to another type of degraded land or has been normalised $(\mathrm{N})$ is shown in Figure 2. 


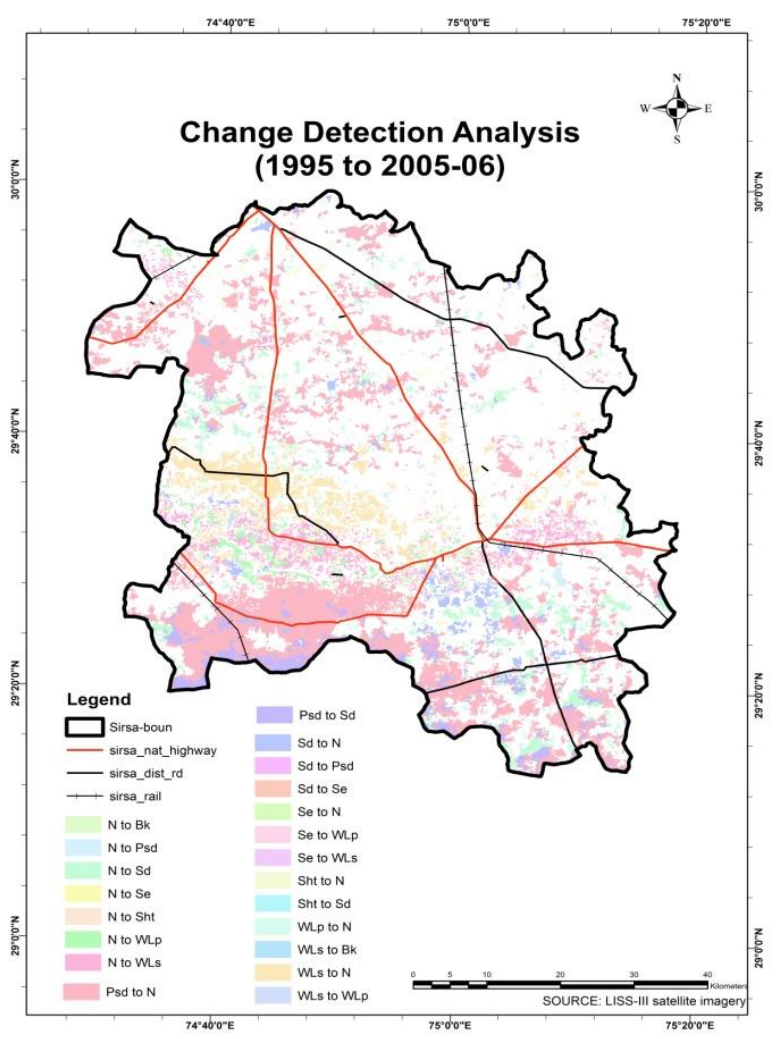

Figure 2. Map showing change in categories of degraded lands (1995 to 2005-06)

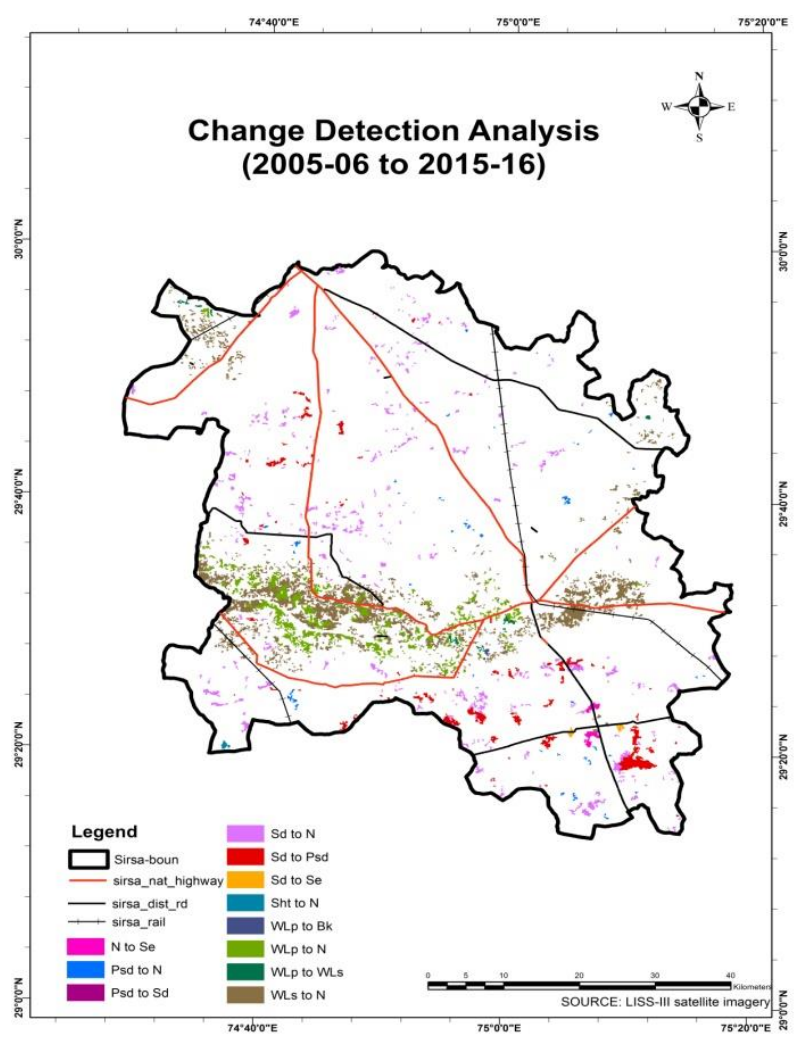

Figure 1. Map showing change in categories of degraded lands ( 2005-06 to 2015-16)

\section{CONCLUSION}

Land degradation is a complex dynamic hazard and a serious global environmental problem. The dynamic nature of degraded soils marks for frequent detection and their identification for its severity and extent over the area. The enormous potential of remote sensing has been utilized to delineate the various features encoding degradation which makes it easier to identify and map large areas at regional as well as global scale. The surface reflectance provided by multispectral satellite sensors makes it easier to identify and map kind of degradation occurring in a particular area. They are also cost effective and time saving. Field studies owe to accuracy of remotely sensed data and provide better understanding. Although a decline in total degraded lands has been observed in the district, but however anthropogenic activities have shown a tremendous increase.

\section{ACKNOWLEDGEMENTS}

The first author is thankful to UGC-BSR fellowship for the financial assistance to carry out the Ph. D work at Department of Environment Science and Engineering, Guru Jambheshwar University of Science and Technology, Hissar. The help extended by the Chief Scientist, HARSAC, Hisar for granting the facilities at HARSAC is also thankfully acknowledged.

\section{REFERENCES}

Ahmad, N. and Pandey, P., 2017. Assessment and Monitoring of Land Degradation Using Geospatial Technology in Bathinda District, Punjab, India. Solid Earth, pp. 1-21.

Kapoor, AS. and Kavdia.,1994. Drainage and salinity problems in Indira Gandhi canal project area. In planning for sustainability in irrigation. Rawat publications, Jaipur, India.

Kassas, M., 1995. Desertification: a general review. Journal of Aris Environments 30, pp. 115-128.

Mandal, AK., 2016. Mapping and characterization of saltaffected and waterlogged soils in the Gangetic plain of central Haryana (India) for reclamation and management. Cogent Geoscience 2, pp. 1-17.

Mandal, AK. and Sharma, RC., 2005. Computerized database on salt affected soils of Haryana state. Indian Society of Remote Sensing 33, pp. 447-455.

Oldeman, LR. Hakkeling, RTA. Sombrock, WG., 1990. World map of the status of human induced soil degradation-GLASOD. Wageningen: ISRIC.

Raina, P., 1994. Assessment of soil degradation hazards in Jalor and Ahor tehsil of Jalor district by remote sensing. Indian Society of Remote Sensing 22(3), pp. 172-180.

Raina, P., 1999. Soil degradation assessment through remote sensing and its impact on fertility status of soils of western Rajasthan. Agro-pedology 9, pp. 30-40.

Raina, P. Kumar, M. Singh, M., 2009. Mapping of Soil Degradation Hazards by Remote Sensing in Hanumangarh District (Western Rajasthan). Indian Society of Remote Sensing 37, pp. 647-657. 
Saxena, R., Verma, KS. Barthwal, AK., 1991. Assessment of Land degradation Hazards, Etah District Uttar Pradesh using Landsat Data. J. Indian Soc. Remote Sensing 19(2), pp. 83-94.

Sehgal, JL. Sharma, PK., 1988. An inventory of degraded soils of Punjab using remote sensing techniques. Soil Survey and Land Evaluation 8, pp. 166-175.

Smith, J., 2000. Remote sensing to predict volcano outbursts. In: The International Archives of the Photogrammetry, Remote Sensing and Spatial Information Sciences, Vol. XXVII-B1, pp. 456-469.

Wang, T. Yan, CZ. Song, X. Li, S., 2011. Landsat images reveal trends in the Aeolian Desertification in a source area for sand and dust storms in China's Alashan Plateau (1975-2007). Land Degradation and Development, pp. 1-5. 